\title{
A Method for the Determination of Plasma Renin Activity in Small Samples
}

\author{
Masashi ImaI, M.D. and Hirofumi SoKabe, M.D.
}

In order to establish a reliable method for the determination of plasma renin activity in small samples, we have compared the methods reported. The method of Boucher et al. was found to be reliable, and modified in the laboratory. Expression of renin activity by the first order reaction constant was emphasized.

$\mathrm{T}$

HE importance of renin-angiotensin system in the regulation of sodium and potassium balance through the control of aldosterone secretion has now been well-recognized.11,2) Although disturbances of electrolytes metabolism are prevalent among pediatric disorders, systematic works on reninangiotensin system are lacking in this field. The main difficulty is unavailability of enough amount of samples. We have devised a method for the determination of plasma renin activity in small samples, based on the method of Boucher et al. ${ }^{3)}$ The points of modification are as follows : (1) All the system are reduced to treat the samll amount of plasma samples. (2) Angiotensinogen in the plasma is also determined by incubating with an excess of renin, and plasma renin activity is expressed as the reaction constant of first order kinetics. ${ }^{4)}$

The renin-angiotensinogen reaction has been shown to follow a first order reaction by Plentl and Page. ${ }^{5)}$ In a system containing an excess amount of substrate the reaction may progress as zero order with a certain limitation, but in the system utilizing plasma as the substrate the reaction follows rather first order in general. When plasma renin activity is relatively high, expression of the activity as the amount of angiotensin formed would be erroneous. This has been also suggested by Bumpus. ${ }^{6)}$

The purpose of this report is to describe detail of the method and to present data of the basic examinations, showing direct evidences that the reaction can be approximated by the first order kinetics in our system.

\section{METHODS}

Collection of plasma : Blood was obtained through a polyethylene cannula (PE-60)

From the Department of Pediatrics (Director: Prof. T. Takatsu), Faculty of Medicine, University of Tokyo and the Department of Pharmacology, Toho University School of Medicine, Tokyo.

Received for publication April 12, 1967. 
inserted into the carotid artery in rats anesthetized with pentobarbital sodium (50 mg./Kg., intraperitoneally) and treated with heparin (100 units/Kg., intravenously). In human blood was drawn from the antecubital vein with a heparinized syringe. The blood was cooled immediately and centrifuged at $0^{\circ} \mathrm{C}$, at $3,000 \mathrm{rpm}$, for $15 \mathrm{~min}$. The plasma was stored at $-20^{\circ} \mathrm{G}$. Experiments were carried out in the rat material first because of its ready availability, and then extended to the human.

Preparation of renin: Renin was prepared from kidney tissue as reported previously." Kidneys of autopsy subjects without hypertension, adrenal, or renal diseases were used for the preparation of human renin. Crude kidney extract was acidified to $\mathrm{pH} 3.0$ with $1 \mathrm{~N} \mathrm{HCl}$ and incubated at $0^{\circ} \mathrm{C}$ for $30 \mathrm{~min}$. It was, then, adjusted to $\mathrm{pH} 5.5$ with $1 \mathrm{~N} \mathrm{NaOH}$, and centrifuged at $0^{\circ} \mathrm{C}$, at $12,000 \mathrm{rpm}$, for $15 \mathrm{~min}$. Supernatant fluid was used as the original solution of renin (designated as $1 / 1$ concentration). Only the preparations compatible with the following criteria were used: (1) the boiled preparation shows no pressor activity in the assay rat, (2) no pressor activity is detected when incubated in substrate free medium, and (3) renin content expressed as the reaction constant is over $5 \times 10^{-2}$ per original concentration $(1 / 1)$.

Incubation system and extraction of angiotensin: Heparinized plasma was adjusted to $\mathrm{pH} 5.5$ with $1 \mathrm{~N} \mathrm{HCl}$ by $\mathrm{pH}$ indicator paper, and filtered on glass wool. About $4 \mathrm{ml}$. of plasma was incubated with $0.5 \mathrm{ml}$. of $3.8 \%$ diammonium ethylenediamintetraacetate (ammonium EDTA) at $37^{\circ} \mathrm{C}$ for $180 \mathrm{~min}$. vigorously shaking in a siliconized Erlenmeyer flask containing $2 \mathrm{ml}$. of moist Dowex 50W-X2 $\left(\mathrm{NH}_{4}^{+}\right)$resin. If the sample was smaller than $2 \mathrm{ml}$., it was diluted with $0.2 \mathrm{M}$. ammonium acetate buffer ( $\mathrm{pH}$ 5.5) and incubated for longer duration. Following the incubation, the mixture was cooled immediately in ice and was transferred on a glass column of $8 \mathrm{~mm}$. in diameter already containing $1 \mathrm{ml}$. of Dowex $50 \mathrm{~W}-\mathrm{X} 2$ resin. The column was maintained at $0^{\circ} \mathrm{C}$ in a specially designed ice box at this step, and was washed firstly with $10 \mathrm{ml}$. of $0.2 \mathrm{M}$. ammonium acetate buffer ( $\mathrm{pH} \mathrm{6.0)}$ secondly with $15 \mathrm{ml}$. of $10 \%$ acetic acid, and finally with $10 \mathrm{ml}$. of distilled water. These eluates were discarded. Then the column was transferred to room temperature. Angiotensin was eluated with $10 \mathrm{ml}$. of $0.1 \mathrm{~N}$ diethylamine followed by $10 \mathrm{ml}$. of $0.2 \mathrm{~N}$ ammonium hydroxide. The eluate was not acidified to avoid ammonium acetate formation which usually showed depressor activity in the bioassay, but immediately evaporated to dryness at $45^{\circ} \mathrm{C}$ by a rotatory evaporator. The dry residue was dissolve in $3 \mathrm{ml}$. of $80 \%$ ethanol and evaporated to dryness. This was repeated 5 more times dissolving in $2 \mathrm{ml}$. of $80 \%$ ethanol. The final dry residue was dissolved in $0.6 \mathrm{ml}$. of $0.9 \%$ saline.

Determination of angiotensinogen: Angiotensinogen was determined by incubating 0.1 to $0.2 \mathrm{ml}$. of plasma with an excess of renin. Volume of renin solution and length of incubation time necessary to provide maximum angiotensin formation were examined. Amount of angiotensinogen was expressed in $\mathrm{ng}$. of maximum amount of angiotensin formed per ml. of the plasma.

Determination of angiotensinase activity: A known amount of angiotensin was added to plasma or hemolyzed red blood cell solution and incubated at $37^{\circ} \mathrm{C}$. Red blood cell solution was made as reported previously, ${ }^{8)}$ and used for the source of angiotensinases because it contains a large amount of angiotensinases, having similar characteristics to those of plasma. Angiotensinase activity was expressed as per 
cent of angiotensin degraded during incubation.

Assay of angiotensin: Angiotensin was assayed by its pressor activity in the rats anesthetized with pentobarbital sodium $(50 \mathrm{mg}$. $/ \mathrm{Kg}$., intraperitoneally) and treated with pentolinium tartrate $(5 \mathrm{mg}$. $/ \mathrm{Kg}$., intravenously). With samples containing diisopropyl fluorophosphate (DFP), rats were treated also with atropine sulfate $(0.5 \mathrm{mg}$. $/ \mathrm{Kg}$., intravenously). The bracket method was used throughout the assay. ${ }^{7)}$

Expression of renin activity: Renin activity was expressed as the reaction constant of first order kinetics:

$$
\mathbf{K}=\frac{2-\log _{10} 100\left(\frac{\mathrm{M}-\mathrm{X}}{\mathrm{M}}\right)}{t} \times 2.30
$$

where, $\mathbf{M}$ is amount of angiotensinogen ( $\mathrm{ng} . / \mathrm{ml}$.), $\mathrm{X}$ is amount of angiotensin formed during a given incubation time (ng./ml.), and $t$ is incubation time (min.).

\section{Results}

1. Inhibition of angiotensinase activity

Effect of $\mathrm{pH}$ and dialysis on angiotensinase activity in rat plasma was shown in Fig. 1. At pH 7.0, 90\% of angiotensin was degraded during incuba-

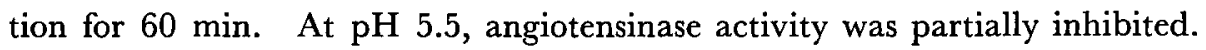
After incubation for $60 \mathrm{~min} .60 \%$ of angiotensin was degraded. Dialysis of the plasma against 100 volumes of cold distilled water $\left(0\right.$ to $\left.4^{\circ} \mathrm{C}\right)$ stirring for 24 hours did not affect angiotensinase activity.

Effect of Dowex 50W-X2 resin and DFP on angiotensinase activity at pH 5.5 in presence of EDTA was shown in Table I. To $0.1 \mu \mathrm{g}$. of angiotensin was added $10 \%$ red blood cell solution in $0.2 \mathrm{M}$. ammonium acetate buffer

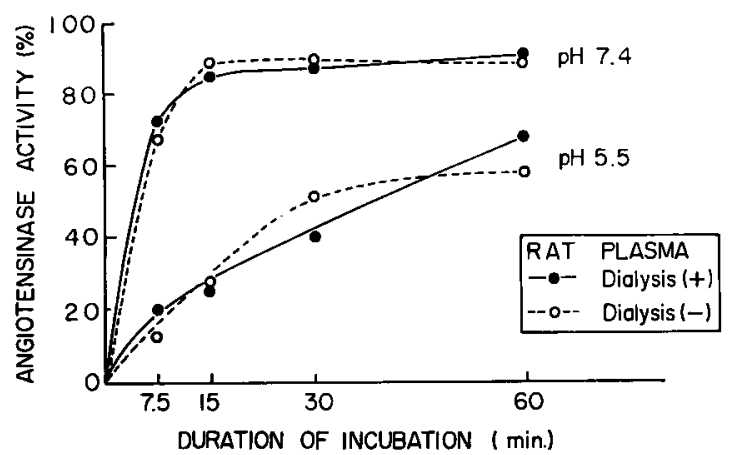

Fig. 1. Effect of $\mathrm{pH}$ and dialysis on angiotensinase activity in rat plasma. Each $0.5 \mathrm{ml}$. of $0.4 \mathrm{ng}$. of synthetic angiotensin, rat plasma, and $1 / 15 \mathrm{M}$ phosphate buffer were mixed, and incubated at $37^{\circ} \mathrm{C}$. 
Table I. Effect of Dowex 50W-X2 Resin and DFP on Angiotensinase Activity in Red Blood Cell Solution

\begin{tabular}{l|cccc}
\hline \multicolumn{1}{c|}{ Experiment } & A & B & G & D \\
\hline Dowex 50W-X2 $\left(\mathrm{NH}_{4}^{+}\right)$ & $(+)$ & $(+)$ & $(-)$ & $(-)$ \\
DFP (1 mg./ml.) & $(-)$ & $(+)$ & $(+)$ & $(-)$ \\
\hline EDTA (3.8 mg./ml.) & $(+)$ & $(+)$ & $(+)$ & $(+)$ \\
\hline No. of Experiments & 7 & 6 & 6 & 6 \\
\hline Angiotensinase Activity (\%) & $4 \pm 7 *$ & $25 \pm 19$ & $23 \pm 8$ & $50 \pm 2$
\end{tabular}

* Figures are mean \pm standard deviation.

( $\mathrm{pH} 5.5$ ) containing $10^{-2} \mathrm{M}$. ammonium EDTA. The mixture was incubated at $37^{\circ} \mathrm{C}$ for $180 \mathrm{~min}$. Angiotensin was semipurified through Dowex $50 \mathrm{~W}-\mathrm{X} 2$ resin $\left(\mathrm{NH}_{4}^{+}\right)$in this experiment. The results showed that angiotensinases were only partially inhibited by adjusting $\mathrm{pH}$ to 5.5 and adding EDTA. Dowex $50 \mathrm{~W}-\mathrm{X} 2$ resin was the best in inhibiting angiotensinase activity at $\mathrm{pH} 5.5$ in presence of EDTA. DFP could inhibit angiotensinase activity to a certain extent, but seemed to interfere adsorption or elution of angiotensin.

2. Examinations of detail of the method

(i) Enzyme kinetic analysis of kidney renin To $0.5 \mathrm{ml}$. of rat plasma was added $0.5 \mathrm{ml}$. of various concentrations of rat renin in the medium containing $0.5 \mathrm{ml}$. of $3.8 \%$ ammonium EDTA, $3.5 \mathrm{ml}$. of $0.2 \mathrm{M}$. ammonium acetate buffer $(\mathrm{pH} 6.0)$, and $2 \mathrm{ml}$. of moist Dowex $50 \mathrm{~W}-\mathrm{X} 2\left(\mathrm{NH}_{4}^{+}\right)$resin. The mixture

CONCN. OF KIDNEY EXTRACT

$\bullet \cdots 1 / 2,0 \cdots 1 / 4, \cdots 1 / 10$

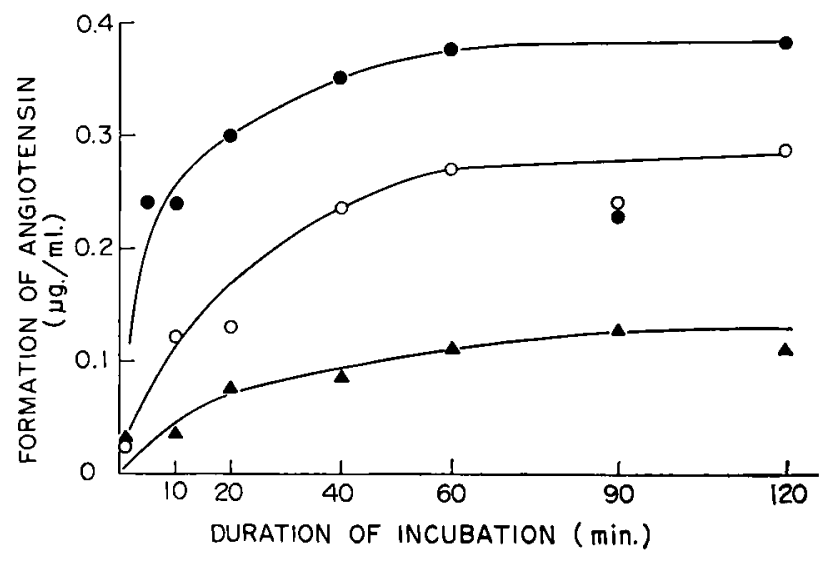

Fig. 2. Effect of incubation time on formation of angiotensin. 
was incubated vigorously shaking at $37^{\circ} \mathrm{C}$. Formation of angiotensin was plotted against incubation time. These curves showed the characteristics of first order reaction (Fig. 2).

To $0.5 \mathrm{ml}$. of rat or human plasma was added $0.5 \mathrm{ml}$. of various concentrations of kidney renin of each species. The mixture was incubated in the above medium for 60 and $180 \mathrm{~min}$., respectively. Formation of angiotensin was plotted against concentration of kidney extract (Fig. 3). The relationship was not always linear as shown with human kidney. However, a linear relationship was obtained between concentration of renin and the reaction constant of first order kinetics (Fig. 4).

The data of enzyme kinetic experiments with rat and human renin were analyzed and expressed as the Lineweaver-Burk plot of the Michaelis-Menten equation (Fig. 5). The Michaelis constants $\left(K_{m}\right)$ of both rat and human renin were approximately equal, and the value was $500 \mathrm{ng} . / \mathrm{ml}$.

(ii) Enzyme kinetic analysis of plasma renin Eleven samples of each $2 \mathrm{ml}$. of a pooled rat plasma were incubated in various concentrations, and velocity of angiotensin formation was determined (Fig. 6). In first order kinetics the velocity of reaction is expressed as follows:

$$
v=k_{1}[\mathrm{E}][\mathrm{S}]
$$

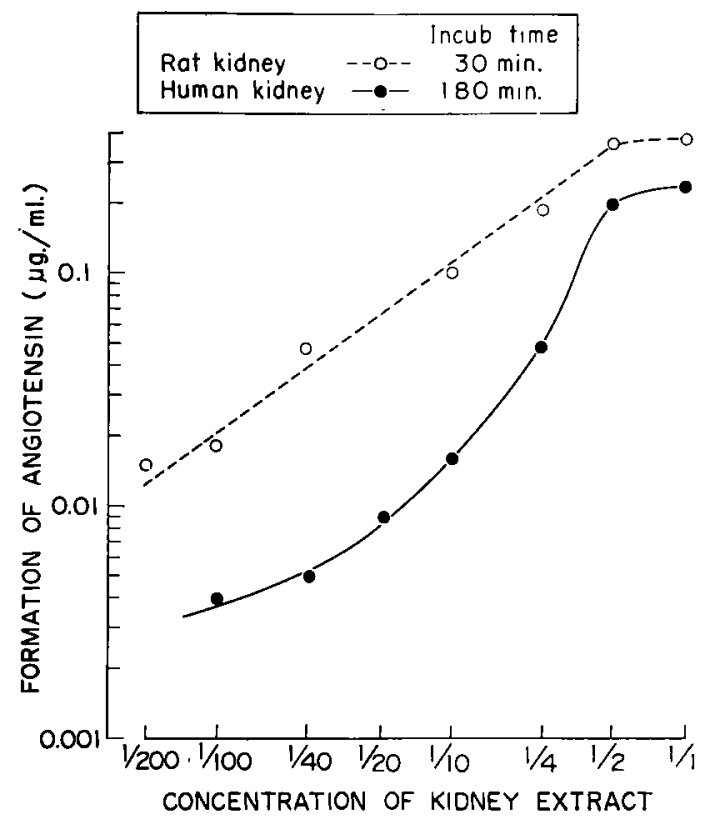

Fig. 3. Formation of angiotensin by various concentration of the kidney extract. 


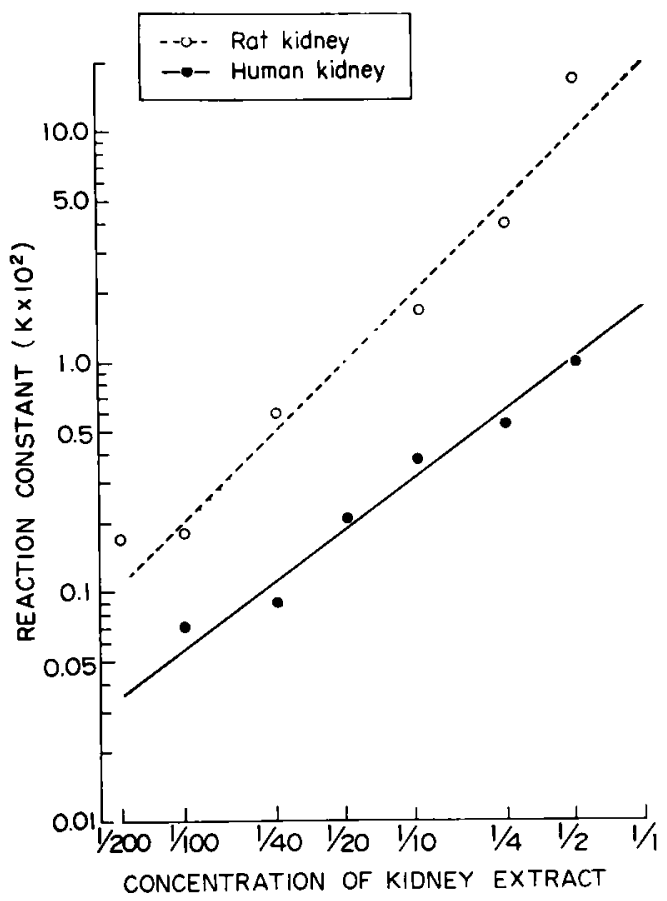

Fig. 4. Correlation of the reaction constant with concentration of the kidney extract.

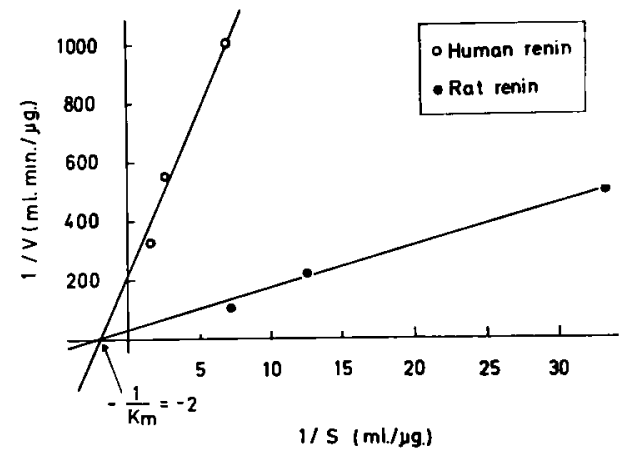

Fig. 5. Determination of the Michaelis constant by means of the Lineweaver-Burk plot.

where $v$ is velocity of reaction, $k_{1}$ is constant of reaction, [E] is concentration of enzyme, and [S] is concentration of substrate. Since both renin and angiotensinogen exist in plasma, they are diluted in the same degree: $[\mathrm{S}]=$ $k_{2}[\mathrm{E}]$. Consequently, velocity is expressed as : $v=k_{1} k_{2}[\mathrm{E}]^{2}=k_{3}[\mathrm{E}]^{2}$. Dotted line in Fig. 4 indicates this theoretical curve, which accords with the 


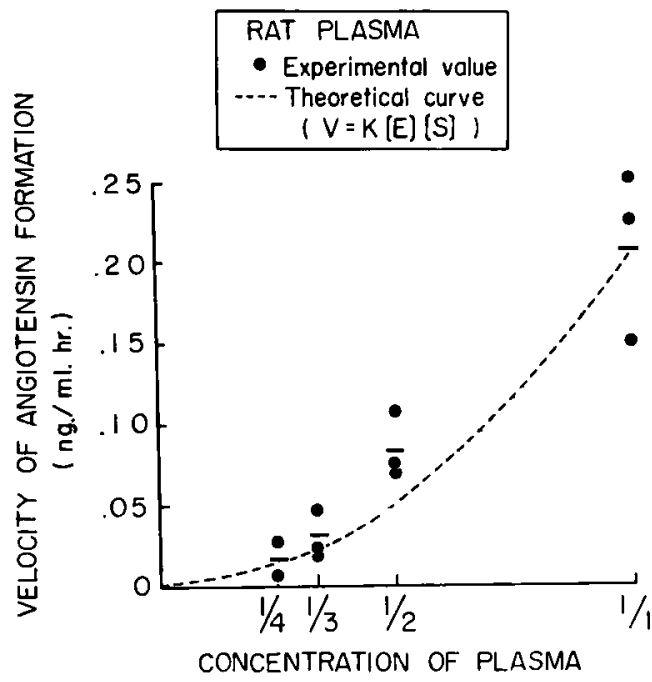

Fig. 6. Velocity of angiotensin formation in the diluted rat plasma.

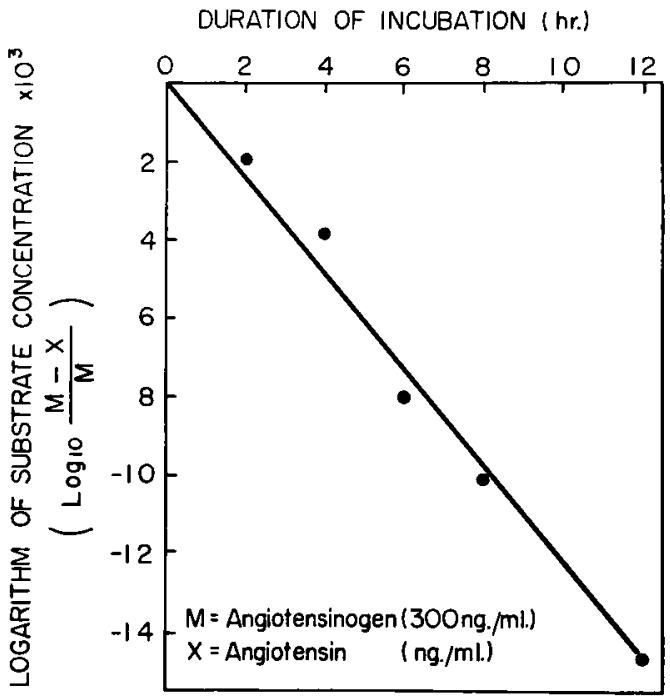

Fig. 7. Evidence for a first order reaction with the plasma renin in human. A human plasma sample containing $300 \mathrm{ng} . / \mathrm{ml}$. of angiotensinogen was incubated for various length of time up to 12 hours. Logarithmic value of substrate concentration was plotted against incubation time.

experimental result.

In order to obtain further evidence for first order reaction, a human plasma containing $300 \mu \mathrm{g} . / \mathrm{ml}$. of angiotensinogen was incubated for longer 
duration up to 12 hours. Logarithmic value of the substrate concentration showed a linear correlation with incubation time (Fig. 7). This observation was consistent with the result which Plentl and $\mathrm{Page}^{4}$ ) had already demonstrated in kinetic analysis of kidney renin.

(iii) Determination of angiotensinogen Angiotensinogen content of the plasma was determined by incubating $0.2 \mathrm{ml}$. of plasma with an excess of renin. More than $0.8 \mathrm{ml}$. of kidney extract in original concentration was necessary to provide maximum angiotensin formation incubating for $120 \mathrm{~min}$. (Fig. 8).

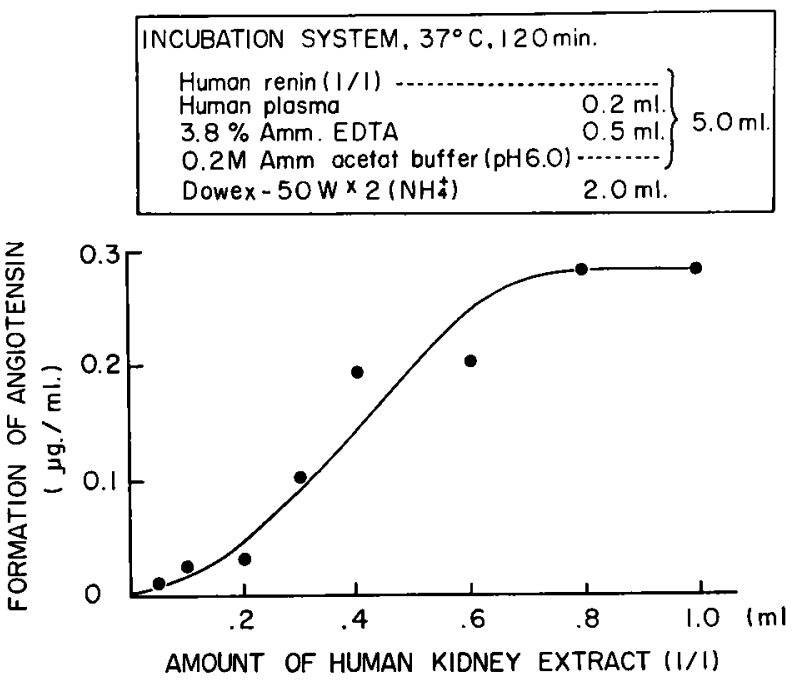

Fig. 8. The amount of human kidney extract necessary to yield the maximum angiotensin formation from plasma.

3. Recovery and reproducibility.

The final method in our laboratory for the determination of plasma renin activity consists of the following major steps :

(1) Adjustment of $\mathrm{pH}$ of heparinized plasma to 5.5.

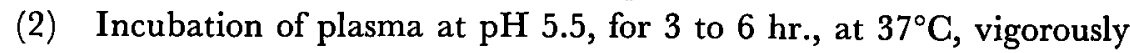
shaking with Dowex 50W-X2 $\left(\mathrm{NH}_{4}^{+}\right)$resin and EDTA.

(3) Incubation of plasma with an excess of kidney renin for $2 \mathrm{hr}$. under the similar condition.

(4) Elution of angiotensin formed and adsorbed on the resin by column chromatography, evaporation, and purification.

(5) Bioassay of the angiotensin by pressor activity in rats.

(6) Calculation of the reaction constant.

Details of the procedures are shown in Fig. 9 as a flow-sheet. 

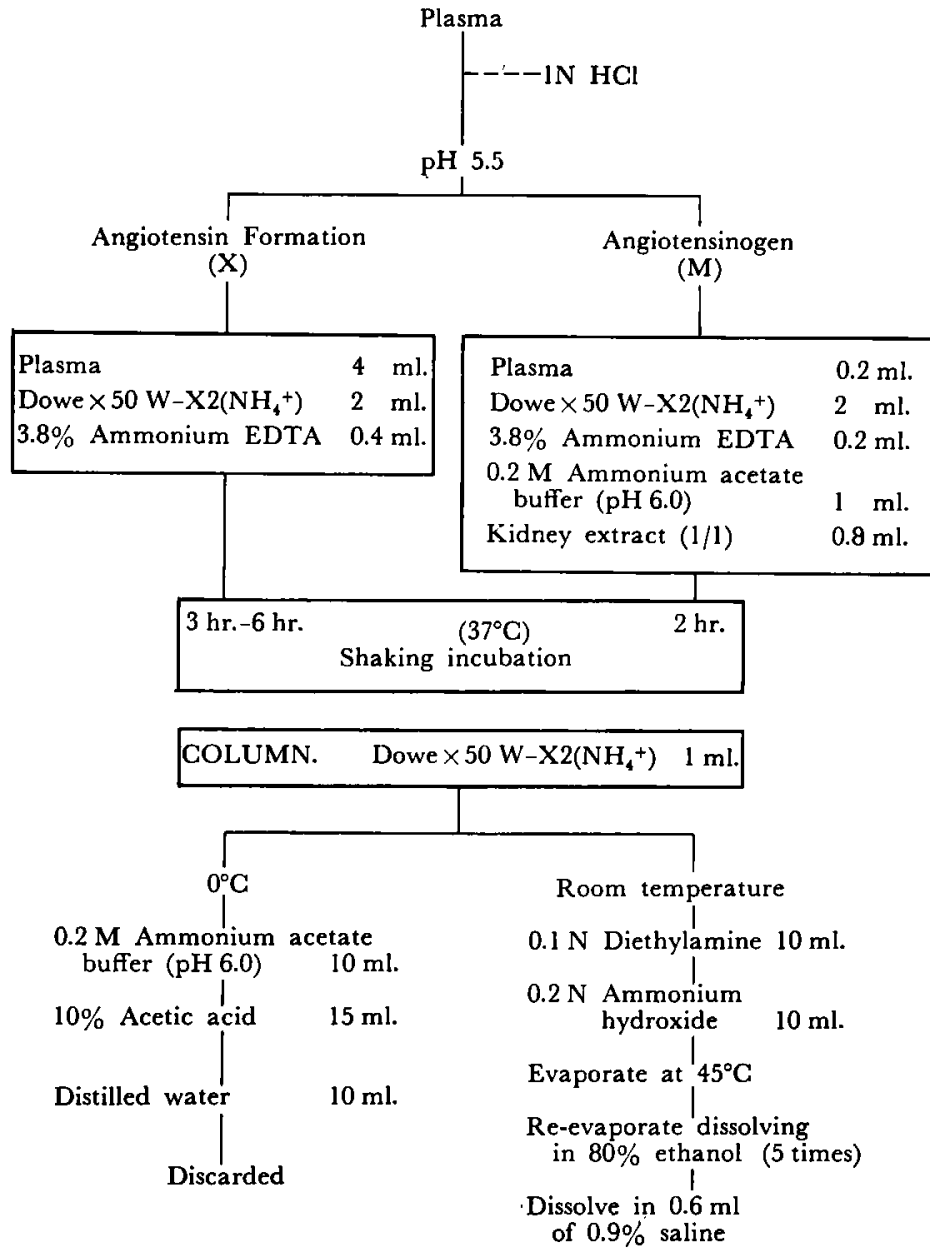

$$
\mathrm{K}=\frac{2-\log _{10}\{(\mathrm{M}-\mathrm{X} / \mathrm{M}) \times 100\}}{\mathrm{t}} \times 2.30
$$

Fig. 9. Flow sheet for the determination of plasma renin activity.

Recovery of angiotensin at the steps of elution, evaporation, and purification was examined by adding 0.05 to $0.25 \mu \mathrm{g}$. of synthetic angiotensin II to the column containing $3 \mathrm{ml}$. of Dowex $50 \mathrm{~W}-\mathrm{X} 2\left(\mathrm{NH}_{4}^{+}\right)$resin. In 10 experiments mean and standard deviation of the recovery was $82 \pm 15 \%$, ranging 60 to $110 \%$. Recovery of angiotensin throughout the whole procedures was also examined by adding angiotensin II to human plasma. The result was $74 \pm 12 \%$, ranging 63 to $90 \%$ in 6 examinations. 
Reproducibility was examined in two different ways. At first duplicate estimations of plasma renin activity were performed in 4 rat plasma samples. The mean per cent differences between two aliquots was $23 \pm 12 \%$, ranging 11 to $39 \%$. Secondly eight aliquots of $0.2 \mathrm{ml}$. of a pooled rat plasma sample were incubated with $0.3 \mathrm{ml}$. of rat renin (1/2) in $4.5 \mathrm{ml}$. of $0.2 \mathrm{M}$. ammonium acetate buffer ( $\mathrm{pH} \mathrm{6.0)}$ containing $10^{-2} \mathrm{M}$. ammonium EDTA at $37^{\circ} \mathrm{C}$ for $60 \mathrm{~min}$. The results also indicated good reproducibility as shown in Table II.

Table II. Reproducibility of the Method

\begin{tabular}{c|c}
\hline Experiment No. & Formation of Angiotensin ng./ml. \\
\hline 1 & 160 \\
2 & 170 \\
3 & 160 \\
4 & 160 \\
5 & 140 \\
6 & 160 \\
7 & 120 \\
8 & 130 \\
\hline Mean \pm S.D. & $150 \pm 18$
\end{tabular}

\section{Discussion}

Various methods have been reported for the determination of peripheral plasma renin activity in human..$^{3,4), 91-14)}$ The method of Brown et al.10) is reasonable in principle, since renin is extracted from the plasma to separate the endogenous angiotensinogen and angiotensinases, and incubated with a fixed concentration of a standard substrate. But its difficulties are in the complex procedures and in the poor recovery. The purified renin preparation becomes unstable. The other methods utilize the angiotensinogen in the plasma, and renin activity is determined by incubating the plasma after some treatments. The methods are simpler and minimize loss of renin. However, angiotensinases were present in the system and the results were consequently deviated. The purpose of various modifications has been how to eliminate angiotensinase activity.

The method of Helmer and Judson ${ }^{4)}$ is simple, but suppression of angiotensinases is incomplete as shown in this paper and elsewhere. ${ }^{8)}$ Boucher et al. ${ }^{3)}$ reported a new method using Dowex 50W-X2 resin, adsorbing the angiotensin formed during incubation and protecting from angiotensinases. Recently, Pickens et al. ${ }^{11}$ tried to inhibit angiotensinase activity by DFP and claimed that it was effective enough. EDTA has been also reported to be able 
to suppress angiotensinases by eliminating calcium ion. ${ }^{16)}$ But it can suppress only a kind of angiotensinases of optimum $\mathrm{pH}$ at 7.4. Our data indicate that Dowex 50W-X2 resin is reliable for the suppression of angiotensinases in presence of EDTA at pH 5.5 at $37^{\circ} \mathrm{C}$.

We have used the reaction constant of first order kinetics to express the renin activity, since the reaction in our incubation system follows approximately a first order and since we can show a linear correlation between the reaction constant and concentration of renin (Fig. 4). Large $\mathrm{K}$ is used in this special case instead of small $k^{4)}$ Although it has been suggested to use the initial velocity by multiplying the reaction constant by the Michaelis constant, we simply used the reaction constant to express the renin activity. Because our system is no longer in the standard condition, and it is the simplest and enough for the purpose of relative comparison of clinical data. Determination of the Michaelis constant is not simple procedures.

On the assumption that the renin-angiotensinogen reaction follows the Michaelis-Menten hypothesis, theoretically from the equation of enzyme kinetics : :5 $^{-15}$

$$
v=\frac{k_{+2}[\mathrm{E}][\mathrm{S}]}{K_{m}+[\mathrm{S}]}
$$

where $v$ is velocity of reaction, $k_{+2}$ is the velocity constant, [E] is concentration of enzyme, $[\mathrm{S}]$ is concentration of substrate, and $K_{m}$ is the Michaelis constant. We have : $v=k_{+2}[\mathrm{E}]$, only when: $[\mathrm{S}] \gg K_{m}$. The equation indicates the zero order reaction. We also have : $v=k_{+2}[\mathrm{E}][\mathrm{S}] / K_{m}$, only when : $[\mathrm{S}] \ll K_{m}$. This is the first order reaction. Assuming the errors in the procedures at least $10 \%$ (see reproducibility), [S] must be more than 10 times of $K_{m}$ to realize that the reaction follows approximately zero order. While [S] must be less than $1 / 10$ of $K_{m}$ to satisfy that the reaction follows approximately first order. In our results, the Michaelis constant is $500 \mathrm{ng} . / \mathrm{ml}$., and angiotensinogen in human plasma ranges 99 to $360 \mathrm{ng} . / \mathrm{ml}$., which are nearly equal. In addition, amount of angiotensionogen in plasma is variable in different diseases and in stages of diseases. ${ }^{14), 17)-19)}$ Most investigators ${ }^{3), 51,91,11)-13 \text { ) }}$ except Helmer and Judson ${ }^{4)}$ expressed plasma renin activity as amount of angiotensin formed during a fixed incubation time. They regarded the reninangiotensinogen reaction in plasma as zero order, merely because angiotensin formation increases linearly during incubation, or because there is a linear correlation between amount of renin and angiotensin formation in a plasma sample. However, the gradient of curve or rate of angiotensin formation would already different depending on the amount of angiotensinogen. Therefore, it is quite misleading to use angiotensin formation for the expression of renin 
activity when the plasma is incubated without purification of renin and angiotensinogen. More than $5,000 \mathrm{ng} . / \mathrm{ml}$. of the substrate must be present in the incubation medium, in order to regard the renin-angiotensinogen reaction as zero order. The trial of Haas and Goldblatt ${ }^{20)}$ in expressing the renin activity by $k_{3}\left(k_{+2}\right)$, therefore, may be significant, although it requires relatively complicated procedures.

\section{SumMary}

(1) Effects of Dowex 50W-X2 resin, diisopropyl fluorophosphate, and incubation at $\mathrm{pH} 5.5$ were compared for inhibiting angiotensinase activity in plasma with $0.93 \times 10^{-2} \mathrm{M}$ EDTA. We found that Dowex $50 \mathrm{~W}-\mathrm{X} 2$ is reliable.

(2) The method of Boucher et al. for determination of plasma renin activity using the Dowex resin was re-examined. We modified the procedures for the determination in small amount of samples.

(3) We measured angiotensinogen content of the plasma simultaneously, and expressed renin activity by the reaction constant of first order kinetics $(\mathbf{K})$, since a linear correlation was found between amount of renin and the reaction constant.

(4) Evidences were presented that the cource of plasma renin-angiotensinogen reaction can be also approximated by the first order kinetics in our system.

(5) Recovery of angiotensin throughout the procedures was $74 \pm 12$ (standard deviation) \%. The results were sufficiently reproducible.

\section{ACKNOWLEDGMENT}

We would like thank to Prof. Tadao Takatsu for his encouragement and approval for the publication of this work.

\section{REFerences}

1. Davis, J. O.: Physiologist 5: 65, 1962.

2. Peart, W. S.: Pharmacol. Rev. 17: 143, 1965.

3. Boucher, R., Veyrat, R., De Champlain, J., and Genest, J.: Canad. Med. Ass. J. 90: 194, 1964.

4. Helmer, O. M. and Judson, W. E.: Circulation 27: 1050, 1963.

5. Plentl, A. T. and Page, I. H.: J. Exp. Med. 78: 367, 1943.

6. Bumpus, F. M.: Report at the International Symposium on Renal Hypertension, Cleveland, 1966.

7. Kawabe, K. and Sokabe, H.: Jap. Heart J. 6: 51, 1965. 
8. Harigaya, S., Sokabe, H., and Sakai, F.: Jap. Heart J. 7: 66, 1966.

9. Yoshinaga, K., Aida, M., Maebashi, M., Sato, T., Abe, K., and Miwa, I.: Tohoku J. Exp. Med. 80: 32, 1963.

10. Brown, J. J., Davies, D. L., Lever, A. F., Robertson, J. I. S., and Tree, M.: Biochem. J. 93 : 594, 1964.

11. Pickens, P. T., Bumpus, F. M., Lloyd, A. M., Smeby, R. R., and Page, I. H.: Circulat. Res. 17: $438,1965$.

12. Warzynski, R., Demirjian, Y., and Hoobler, S.: Canad. Med. Ass. J. 90 : 225, 1964.

13. De Vito, E. and Fasciolo, J. C.: Acta Physiol. Latinoam. 15: 129, 1965.

14. Gould, A. B., Skeggs, L. T., and Kahn, J. R. : Lab. Invest. 15: 1802, 1966.

15. Yamaura, Y.: Shin Ikagaku (4th ed.), Nanzando, Tokyo, p. 296, 1964 (in Japanese).

16. Khairallah, P. A., Bumpus, F. M., Page, I. H., and Smeby, R. R.: Science 140: 672, 1963.

17. Helmer, O. M.: Canad. Med. Ass. J. 90 : 221, 1964.

18. Veyrat, R., De Champlain, J., Boucher, R., and Genest, J.: Canad. Med. Ass. J.: 90 : 215, 1964.

19. Imai, M., Igarashi, Y., and Sokabe, H.: (in preparation).

20. Haas, E. and Goldblatt, H.: Circulat. Res. 20: 45, 1967. 